\title{
Thymoquinone-loaded ethosome with breast cancer potential: optimization, in vitro and biological assessment
}

\author{
Shilan Nasri ${ }^{1} \cdot$ Bahman Ebrahimi-Hosseinzadeh $^{1}$ (D) Mahdi Rahaie ${ }^{1} \cdot$ Ashrafalsadat Hatamian-Zarmi $^{1}$. \\ Razi Sahraeian ${ }^{2}$
}

Received: 20 May 2019 / Accepted: 11 December 2019 / Published online: 5 February 2020

(c) The Author(s) 2020

\begin{abstract}
Ethosomes are most commonly used vesicular delivery system compared to other lipidic vesicles due to its ethanolic content. Thymoquinone (TQ), the main biologically active complex of Black Cumin seed, has established anticancer activities in several tumors. In this work, the preparation of ethosome for TQ encapsulation by response surface method (RSM) was developed. Central composite design (CCD) was used to optimize three effective parameters involved in ethosome structure including phospholipid, cholesterol and ethanol concentration and the combined effects of them, as well. The obtained optimum values for the variables were phospholipid 5\% (W/W), ethanol 45\% (V/V) and cholesterol 1.5\% (W/W) which were validated by experimental assay. The ethosomal formulation was more characterized for vesicle shape, size, zeta potential and entrapment efficiency percentage. The result showed an efficiency of $99 \%$ for drug entrapment with average vesicle size and zeta potential of $20 \pm 1 \mathrm{~nm}$ and $-63 \pm 2 \mathrm{mv}$, respectively. A quadratic model with a high adequacy $\left(R^{2}\right)$ for size and zeta potential of 0.9319 and 0.9338 , respectively, was resulted from RSM and experimental assay. Thymoquinone (TQ) encapsulated in optimized ethosome. Also, cellular toxicity and release test was done. The toxicity and release curves were obtained and the cytotoxic activity of the ethosomic TQ against MCF-7 cell lines was greater than free TQ. IC50 values of free TQ, ethosomic TQ, were found to be $1.10 \mu \mathrm{g} / \mathrm{ml}, 0.95 \mu \mathrm{g} / \mathrm{ml}$, respectively. The generated model suggests a new approach to prediction and experimental lipidic carriers.
\end{abstract}

\section{Graphic abstract}
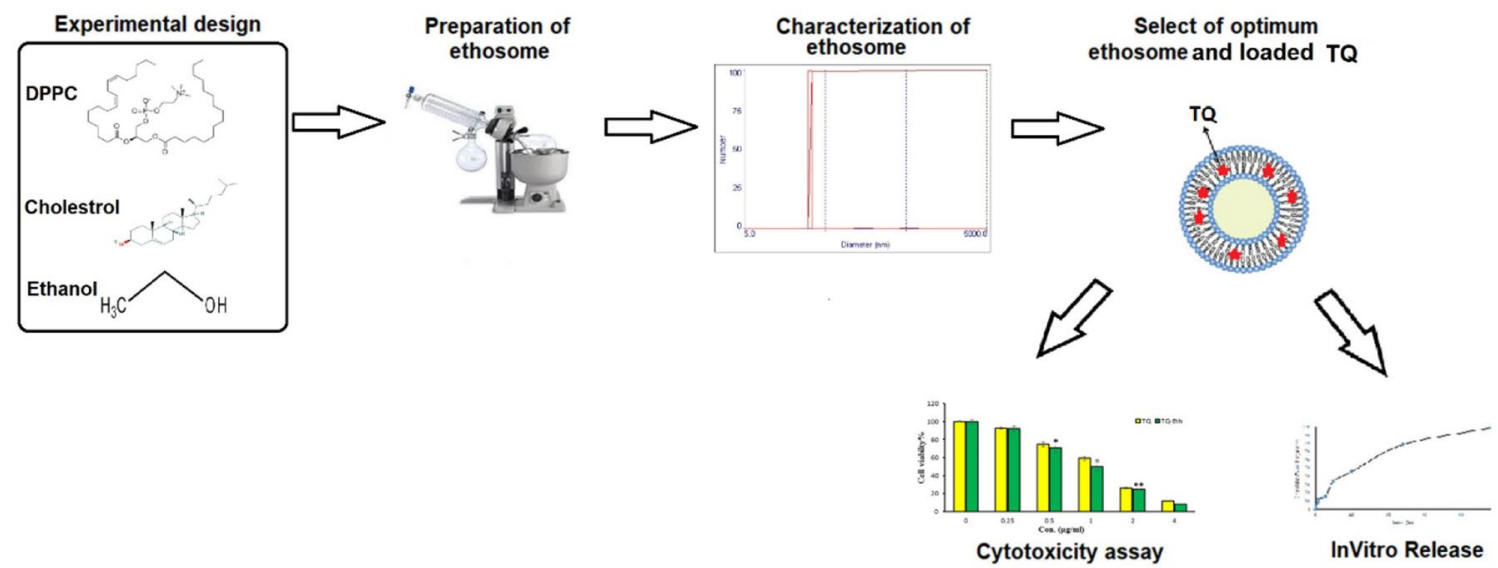

Central composite design (CCD) was used to optimize three effective parameters involved in ethosome structure including phospholipid, cholesterol and ethanol concentration and the combined effects of them, as well. The ethosomal formulation was more characterized for vesicle shape, size, zeta potential and entrapment efficiency percentage. Also, cellular toxicity and release test was done. The toxicity and release curves were obtained and the cytotoxic activity of the ethosomic TQ against MCF-7 cell lines was greater than free TQ.

Extended author information available on the last page of the article 
Keywords Central composite design · Zeta potential - Quadratic model $\cdot$ Thymoquinone $\cdot$ Polymeric nanocarrier

\section{Introduction}

Recently, considerable interest has been focused on transdermal drug delivery system, because of its high efficiency [1]. As a better alternative, transdermal route has been proposed to achieve constant levels of plasma for extended period of time, which also could be advantageous, since it needs less frequent dosing regimens [2].

Transdermal delivery using liposomal formulation has been studied for various purposes. Unfortunately, liposomes have disadvantages such as instability and poor skin permeation that limit their use in Transdermal delivery. Recently, Cevc et al. and Touitou et al. introduced new approach for solving these problems. They formulated ethosome nanocarriers for non-invasive delivery of drugs through the skin. Ethosomes can pass through the stratum corneum easily due to the fact that it contains ethanol and polyols which are penetration enhancer [3].

Bilayer structures of ethosomes, composed of aqueous and lipid, have shown affinity for both lipophilic and hydrophilic drug resulting in enhanced bioavailability. Ethosomes are composed of three main components: cholesterol, phospholipid, and ethanol. The concentration of these three components can influence several properties of ethosomes, including entrapment efficiency, size, and zeta potential [4].

Central composite design-response surface methodology (CCD-RSM) is considered as the preferred method for further optimization of the preparation using nonlinear model to achieve the most fitness with experimental data. RSM has shown higher certitude compared with many other methods, such as uniform design and orthogonal design [4]. Utilizing a critical aspect, the design of experiments (DOE), RSM has been broadly used for the developing, optimizing and validation of formulations. The rapid evaluation of all prospective factors has been permitted by this method in a simultaneous timely manner. Also, this method permits the critical factors to be identified for a specific response, the different levels of these factors to be optimized, and the experimental responses to be modeled. The factorial experimental designs are preferred than traditional optimization to be employed in terms of determining minimum number of experiments and ease in statistical significance evaluation of interactions on dependent variables and independent factors [5]. Several benefits are gained from RSM, including identification of effective factors, selection of optimum conditions, analysis of interactions, as well as qualifying the relationship of one or more measured responses to the vital input factors using limited number of experiments. This methodology has been used to optimize several processes of fermentation [6]. There are three groups of design points in a CCD: fractional factorial or two-level factorial, central and axial points. The purpose of $\mathrm{CCD}$ is to estimate the coefficients of a quadratic model. There are several reports available in the literature on using the central composite design [7-10].

Many nanocarriers have employed RSM for optimization, such as apigenin-loaded transfersomal system [5], nanoethosomes for Transdermal Delivery of Tropisetron $\mathrm{HCl}$ [11], they optimized the concentrations of both phospholipid, ethanol and phospholipid type by Box Behnken design. The formulation of galantamine hydrobromide $(\mathrm{GH})$ was in a gel-type drug reservoir [12]. In other study prepared ethosomes formulation using Box Behnken design (BBD) [4].

Thymoquinone (2-isopropyl-5-methylbenzo-1, 4-quinone) (TQ), the richest essential of the volatile oil also existing in the fixed oil, is the organically active composite of Black Cumin seeds [13].

Thymoquinone has a wide range of beneficial biological and pharmacological properties. It possesses outstanding antioxidant [14] hypoglycemic [15], anti-inflammatory [16], anticancer [17] and hepatoprotective [18] activities beside its immune modulating property [19].

In 2019, Sabrina et al. studied the potential roles of TQ in the prevention and treatment of hepatocellular carcinoma (HCC), by revising the preclinical studies and by highlighting the potential applications of TQ as a therapeutic choice for HCC treatment into clinical practices. These examinations ought to be engaged (1) on the understanding of the molecular mechanism regulated by TQ in HCC; and (2) on the identification of the optimum therapeutic dosage of TQ for intervention trials in HCC patients [20].

In 2019, Shahad et al. performed RNA sequencing to investigate the anticancer mechanisms of TQ-treated $\mathrm{T}$ cell acute lymphoblastic leukemia cell line (Jurkat cells) and examined gene expression using different tools. Their results indicate that the use of TQ as an epigenetic drug represents a promising strategy for epigenetic therapy for both solid and blood tumors by targeting both DNA methylation and histone post-translational modifications [21].

In 2019, Saeed et al. evaluate the antineoplastic potential of TQ and their underlying mechanisms in A549 cells (human lung cancer cell line). Our results proposed that TQ may be a potential new therapeutic agent for the management of lung cancer. TQ promoted apoptosis in A546 lung cancer cells by the activation of p53 and caspase cascadedependent pathways [22].

Despite the promising anticancer activities of TQ, the main limitation for its clinical translation lies in its hydrophobicity, poor bioavailability. Nanoparticle encapsulation of TQ could improve its bioavailability, delivery and targeting capacity as well as protect it from unspecific binding. 
These include polymeric [23], liposomal [24], solid lipid nanocarriers (SLNs) [25] and nanostructured lipid carriers (NLCs) [26],

Altogether, RSM has rarely been employed to optimize ethosome formulation. This work targets three main objectives aiming to better understand the relationships between the concentration of cholesterol, phospholipid and ethanol, which are the three main variables, and zeta potential and size, which are the responses. Also, the other objective of this study is to obtain the optimum conditions for ethosome formulation using fractional factorial experimental design and RSM. An appropriate basis is provided by all the results of this study for further exploration.

\section{Experimental}

All chemicals were received from commercial Sources and used without further purification. Phospholipon 90 and cholesterol were purchased from Sigma-Aldrich (USA). Ethanol, methanol and other solvents were obtained from Merck Company (Germany). Amicon Ultracel $3 \mathrm{~K}$ filter was purchased from Millipore (Massachusetts, USA). TQ ( $\geq 98 \%)$ was purchased from Santa Cruz Biotechnology (USA). Human epithelial breast cancer cell lines MCF-7 were obtained as a gift. Culture media (DMEM) were obtained from Sigma-Aldrich (USA). Fetal calf serum and 1\% L-glutamine (Gibco, UK) and penicillin-streptomycin were purchased from Gibco (UK). Phosphate-buffered saline (PBS) was purchased from Takara Bio Inc. (Otsu, Shiga, Japan).

\section{Preparation of ethosomes}

Ethosomes were prepared by conventional mechanical dispersion method [27]. Briefly, soya lecithin (5\%), ethanol (45\%), and cholesterol (1.5\%) were dissolved in $40 \mathrm{~mL}$ of chloroform at a soy lecithin to cholesterol ratio of 3:1 $(\mathrm{w} / \mathrm{w})$. TQ $(0.1 \%)$ was added to produce a final concentration of $0.02 \%(\mathrm{w} / \mathrm{v})$. Organic solvent was removed by rotary evaporation (Rotavapor, Buchi, Germany) at $37{ }^{\circ} \mathrm{C}$ followed by overnight vacuum drying. The deposited lipid film was hydrated by rotation with $40 \mathrm{~mL}$ of distilled water at $100 \mathrm{rpm}$ for $30 \mathrm{~min}$ at $37^{\circ} \mathrm{C}$. The resultant optimized formulation was selected by Response Surface Method (RSM) optimization.

\section{Evaluation of ethosomes visualization by field emission scanning electron microscope (FESEM)}

The size and shape of the vesicles were observed by the field emission scanning electron microscope (CamScan MV2300, Canada). One drop of ethosomal suspension was mounted on a clear glass stub. Then they were air-dried and coated with a very thin layer of gold to visualize under Field Emission scanning electron microscope at magnification of 200,000x.

\section{Vesicular size and zeta potential}

Dynamic light scattering technique was used to determine the vesicular size, size distribution and polydispersity index (PDI). One drop of ethosomal solution was diluted to $10 \mathrm{ml}$ with hydroethanolic mixture used in the formulation and then, the measurements were taken [28]. The zeta potential was determined by Zetasizer nano (Brookhaven, NY, USA). All the measurements were done at $25^{\circ} \mathrm{C}$.

\section{UV-visible}

Hitachi double-beam spectrophotometer (Hitachi (Pvt) Ltd, Tokyo, Japan) was used to ultraviolet-visible spectra in range of 100-700 nm using dual 1-cm silica cuvettes in ambient condition [29].

\section{Entrapment efficiency analysis}

The chemical nature of lipid is a vital factor influencing the entrapment of drug. TQ entrapment can be measured by Amicon filter centrifugation technique and UV-visible spectrophotometer in ambient condition $\left(25^{\circ} \mathrm{C}\right.$ and pressure $1 \mathrm{~atm}$ ), as well. The entrapment efficiency (EE) of ethosomes was calculated in the first $2 \mathrm{~h}$ of preparation based on the following formula:

$\mathrm{EE}=\frac{C_{\mathrm{t}}-C_{\mathrm{f}}}{C_{\mathrm{t}}} \times 100$,

where $C_{t}$ is the total amount of drug in the ethosome suspension and $C_{f}$ is the amount of the drug that diffused into the receiver medium. The results are reported as the means of three independent treatments (experiments) performed in three replicates [5].

\section{Experimental design}

Design Expert software (stat-ease design-expert 10.0.7 X86/ X64) was used for getting optimized formula for ethosomes synthesis. Central composite, Box-Behnken and Doehlert designs were among the principal RSMs used in the experimental design. The most popular response surface method was the central composite design [30]. The design consists of following parts: (1) a full factorial or fractional factorial design, (2) an additional design (often, a star design) in which the experimental points are at a distance $\alpha$ from its center, and (3) a central point. Full, uniformly routable central composite designs present the following characteristics: 
1. Given the equation below, you need an experiment $(N)$

$N=L^{2}+2 L+c p$,

where $L$ is the number of factors and cp is the replicate number of the central point;

2. The $\alpha$ value depends on the number of variables which can be calculated by:

$\alpha=2^{L / 4}$

$\alpha$ values are $1.41,1.68$, and 2.00 for two, three and four variables, respectively [30].

3. All factors were studied in five levels, $(-\alpha,-1,0,+1$, $+\alpha$ ). Using these levels, enough information could be generated to fit a second-order polynomial called "quadratic". Standard statistical software can compute the actual fitting of the model. Using design of experiments based on RSM, the optimum conditions having satisfactory performance can be obtained with minimum number of experiments without the need for studying all possible combinations experimentally. Furthermore, the input levels of the different variables for a particular level of response can also be determined.

A 5-level design was employed in this study, requiring 20 experiments. The selected variables and levels used to optimize conditions for Ethosome compositions are shown in Table 1. The other operational parameters of ethosome production (i.e., $\mathrm{pH}$ and ambient temperature) were kept constant.

Table 2 shows the factors, levels and experimental design as coded $(-\alpha,-1,0,+1,+\alpha)$ and uncoded (actual values). To avoid bias, 20 runs were performed in a totally random order.

The quadratic equation for the variables is as follows [30]:
Table 1 The level of control variables

\begin{tabular}{llllll}
\hline Variable & Low axial $(-\alpha)$ & $\begin{array}{l}\text { Low factorial } \\
(-1)\end{array}$ & Center $(0)$ & $\begin{array}{l}\text { High factorial } \\
(+1)\end{array}$ & High axial $(+\alpha)$ \\
\hline Et (V/V) & 3.06 & 15.00 & 32.50 & 50.00 & 61.93 \\
$\mathrm{Ph}(\mathrm{W} / \mathrm{W})$ & 0.61 & 3.00 & 6.50 & 10.00 & 12.38 \\
$\mathrm{Ch}(\mathrm{W} / \mathrm{W})$ & 0.15 & 0.70 & 1.05 & 2.84 & 2.84 \\
\hline
\end{tabular}

Table 2 Coded values, actual values, and size and zeta potential responses of different values of variables

\begin{tabular}{|c|c|c|c|c|c|c|c|c|}
\hline Run no. & $\begin{array}{l}\text { Coded value } \\
\text { phospholipid } \\
(\mathrm{W} / \mathrm{W})\end{array}$ & $\begin{array}{l}\text { Coded value of } \\
\text { ethanol }(\mathrm{V} / \mathrm{V})\end{array}$ & $\begin{array}{l}\text { Coded value of } \\
\text { the cholesterol }\end{array}$ & $\begin{array}{l}\text { Actual value } \\
\text { of the ethanol }\end{array}$ & $\begin{array}{l}\text { Actual value of } \\
\text { the phospholipid }\end{array}$ & $\begin{array}{l}\text { Actual value of } \\
\text { the cholesterol }\end{array}$ & Size response & Pz response \\
\hline 1 & $-\infty$ & 0 & 0 & 30.00 & 0.97 & 1.50 & 89.70 & -63.34 \\
\hline 2 & +1 & -1 & -1 & 15.00 & 5.00 & 0.70 & 52.50 & -48.51 \\
\hline 3 & 0 & 0 & 0 & 30.00 & 3.50 & 1.50 & 39.50 & -50.38 \\
\hline 4 & +1 & +1 & +1 & 45.00 & 5.00 & 2.30 & 97.50 & -53.64 \\
\hline 5 & 0 & $-\infty$ & 0 & 4.70 & 3.50 & 1.50 & 65.60 & -46.06 \\
\hline 6 & -1 & -1 & -1 & 15.00 & 2.00 & 0.70 & 21.20 & -66.46 \\
\hline 7 & 0 & 0 & $-\infty$ & 30.00 & 3.50 & 0.15 & 108.00 & -43.67 \\
\hline 8 & -1 & +1 & +1 & 45.00 & 2.00 & 2.30 & 115.00 & -29.76 \\
\hline 9 & 0 & 0 & $+\infty$ & 30.00 & 3.50 & 2.80 & 133.30 & -27.52 \\
\hline 10 & 0 & $+\infty$ & 0 & 55.20 & 3.50 & 1.50 & 102.10 & -32.71 \\
\hline 11 & 0 & 0 & 0 & 30.00 & 3.50 & 1.50 & 40.00 & -45.09 \\
\hline 12 & -1 & +1 & -1 & 45.00 & 2.00 & 0.70 & 141.00 & -41.03 \\
\hline 13 & 0 & 0 & 0 & 30.00 & 3.50 & 1.50 & 60.80 & -47.45 \\
\hline 14 & 0 & 0 & 0 & 30.00 & 3.50 & 1.50 & 48.00 & -47.97 \\
\hline 15 & +1 & -1 & +1 & 15.00 & 5.00 & 2.30 & 81.10 & -32.51 \\
\hline 16 & 0 & 0 & 0 & 30.00 & 3.50 & 1.50 & 47.00 & -49.50 \\
\hline 17 & -1 & -1 & +1 & 15.00 & 2.00 & 2.30 & 133.40 & -48.49 \\
\hline 18 & 0 & 0 & 0 & 30.00 & 3.50 & 1.50 & 45.00 & -50.34 \\
\hline 19 & $+\infty$ & 0 & 0 & 30.00 & 6.02 & 1.50 & 56.30 & -50.77 \\
\hline 20 & +1 & +1 & -1 & 45.00 & 5.00 & 0.70 & 185.00 & -53.57 \\
\hline
\end{tabular}


$Y=\beta_{0}+\sum \beta_{i} x_{i}+\sum \beta_{i i} x_{i}^{2}+\sum \beta_{i j} x_{i} x_{j}$

where $Y, \beta_{0}, \beta_{i}, \beta_{i i}$, and $\beta_{i j}$ are predicted response, a constant, linear coefficient, squared coefficient, and interaction coefficient, respectively. Equation (4) was used to build surfaces for variables [30].

\section{Physical stability study}

Vesicle physical stability was examined by storage of them at $4{ }^{\circ} \mathrm{C} \pm 0.5^{\circ} \mathrm{C}$ temperature. Vesicle size, zeta potential, and entrapment efficiency of the vesicles were measured until 90 days every 30 days [31].

\section{In vitro release}

In vitro ethosome drug release is done by dialysis bag diffusion method. Release studies for ethosomal formulation were performed with dialysis bag method (molecular weight cut-off 12,000 Da). Briefly, $1 \mathrm{ml}$ of ethosomal formulation $(0.1 \% \mathrm{TQ})$ in dialysis bags were immersed in separate vials containing $20 \mathrm{ml}$ of PBS buffer and maintained at $37^{\circ} \mathrm{C}$ with stirring speed of $100 \mathrm{rpm}$. Release samples were collected at $0.25,0.5,0.75,1,2,3,5,10,24$ and $48 \mathrm{~h}$ and replaced with fresh medium at each time point. Collected samples were analyzed for drug content using UV-visible [32].

\section{Cytotoxicity assay}

Cells were seeded at $10^{4}$ per well in 96-well plate with $200 \mu \mathrm{l}$ of fresh complete medium for $24 \mathrm{~h}$ before treatment. All sample solutions were filtered with a $0.22-\mu \mathrm{m}$ syringe filter and diluted into different concentrations with Dulbecco's modified eagle's medium (DMEM). Fresh complete medium $(200 \mu \mathrm{l})$ containing TQ $(25,50$ and $100 \mathrm{mM})$ was added into each well to treat cells for 24,48 , and $72 \mathrm{~h}$. The culture medium was then replaced with 100- $\mu$ l MTT solutions (10\%), and incubated for $4 \mathrm{~h}$. Afterward, the medium was completely removed and $100 \mu \mathrm{l}$ of DMSO was added to each well to extract the formazan products formed by viable cells. The optical density (OD) of extracts was measured at $570 \mathrm{~nm}$ on a microplate reader. The results were expressed as a percentage of the absorbance of the blank control [33].

\section{Statistical analysis}

The nanocarrier optimization was carried on by stat-ease design-expert 10.0.7 X86/X64.

\section{Results and discussion}

The central composite design (CCD) was used to find the suitable variables. The results of CCD experiments consisted of coded, actual and experimental data for studying the effects of three variables, phospholipid. cholesterol and ethanol content, on size and zeta potential responses are presented in Table 2 .

The data were fitted with a second-order polynomial function (Eq. 5). Estimated regression coefficients for the size in the interactions between $A, B$ and $C$ are given in Table $3 \mathrm{a}$. It was found that the quadratic models are useful for forecasting the responses for "size", $\left(Y_{\text {size }}\right)$ as below:

Table 3 Estimated regression coefficients a) size, b) zeta potential

\begin{tabular}{|c|c|c|c|c|c|}
\hline Source & $\begin{array}{l}\text { Sum of } \\
\text { square }\end{array}$ & $d f$ & Mean square & $F$ value & $\begin{array}{l}p \text { value } \\
\text { Prob }>\text { F }\end{array}$ \\
\hline \multicolumn{6}{|l|}{ (a) } \\
\hline Model & 32738.99 & 9 & 3637.67 & 15.19 & 0.0001 \\
\hline $\begin{array}{l}\text { A-Phospho- } \\
\text { lipid }\end{array}$ & 191.74 & 1 & 191.74 & 0.80 & 0.3918 \\
\hline$B$-Ethanol & 7136.32 & 1 & 7136.32 & 29.81 & 0.0003 \\
\hline $\begin{array}{l}C \text {-Choles- } \\
\text { terol }\end{array}$ & 352.16 & 1 & 352.16 & 1.47 & 0.2531 \\
\hline$A B$ & 276.13 & 1 & 276.13 & 1.15 & 0.3081 \\
\hline$A C$ & 2613.64 & 1 & 2613.64 & 10.92 & 0.0080 \\
\hline$B C$ & 8115.38 & 1 & 8115.38 & 33.90 & 0.0002 \\
\hline$A^{2}$ & 1745.88 & 1 & 1745.88 & 7.29 & 0.0223 \\
\hline$B^{2}$ & 3174.90 & 1 & 3174.90 & 13.26 & 0.0045 \\
\hline$C^{2}$ & 11180.52 & 1 & 11180.52 & 46.70 & $<0.0001$ \\
\hline Residual & 2393.99 & 10 & 239.40 & & \\
\hline Lack of fit & 2093.78 & 5 & 418.76 & 6.97 & 0.0263 \\
\hline Pure error & 300.21 & 5 & 60.04 & & \\
\hline Cor total & 35132.98 & 19 & & & \\
\hline \multicolumn{6}{|l|}{ (b) } \\
\hline Model & 1794.17 & 9 & 199.35 & 15.66 & $<0.0001$ \\
\hline $\begin{array}{l}\text { A-Phospho- } \\
\text { lipid }\end{array}$ & 25.47 & 1 & 25.47 & 2.00 & 0.1876 \\
\hline$B$-Ethanol & 119.64 & 1 & 119.64 & 9.40 & 0.0119 \\
\hline $\begin{array}{c}C \text {-Choles- } \\
\text { terol }\end{array}$ & 383.09 & 1 & 383.09 & 30.10 & 0.0003 \\
\hline$A B$ & 618.64 & 1 & 618.64 & 48.60 & $<0.0001$ \\
\hline$A C$ & 22.14 & 1 & 22.14 & 1.74 & 0.2166 \\
\hline$B C$ & 64.81 & 1 & 64.81 & 5.09 & 0.0477 \\
\hline$A^{2}$ & 188.61 & 1 & 188.61 & 14.82 & 0.0032 \\
\hline$B^{2}$ & 99.65 & 1 & 99.65 & 7.83 & 0.0189 \\
\hline$C^{2}$ & 227.08 & 1 & 227.08 & 17.84 & 0.0018 \\
\hline$C$ Residual & 127.28 & 10 & 12.73 & & \\
\hline Lack of fit & 106.50 & 5 & 21.30 & 5.12 & 0.0486 \\
\hline Pure error & 20.78 & 5 & 4.16 & & \\
\hline Cor total & 1921.45 & 19 & & & \\
\hline
\end{tabular}




$$
\begin{aligned}
Y_{\text {size }}= & 46.45-3.75 A+22.86 B+5.08 C+5.88 A B-18.08 A C \\
& -31.85 B C+11.01 A^{2}+14.84 B^{2}+27.85 C^{2} .
\end{aligned}
$$

The analysis of variance (Table $4 a$ ) indicated that the model terms of $B, B^{2}, C^{2}, A C$ and $B C$ were significant ("probe $>P$ " less than 0.05), but $A, C$ and $A B$ were not significant. Thus, the related terms were eliminated because they had $P$ values more than 0.1 and also caused a decrease in the adjusted $R^{2}$ of the model. Therefore, the simplified second-order polynomial equation for ethosome production $(Y)$ in terms of actual factors was expressed as follows:

$$
\begin{aligned}
Y_{\text {size }}= & 46.45+22.86 B-18.08 A C-31.85 B C \\
& +11.01 A^{2}+14.84 B^{2}+27.85 C^{2} .
\end{aligned}
$$

And also for zeta potential, the data were fitted with a second-order polynomial function (Eq. (7)). Estimated regression coefficients for the zeta potential for the interactions between A, B and C are given in Table 3b. Quadratic models to be useful for the response parameter, "zeta potential' $\left(\mathrm{Y}_{\text {zeta }}\right)$, are given as below:

$$
\begin{aligned}
Y_{\text {zeta }}= & -48.52+1.37 \mathrm{~A}+2.96 B+5.30 C-8.79 A B \\
& -1.66 A C-2.85 B C-3.62 A^{2}+2.63 B^{2}+3.79 C^{2} .
\end{aligned}
$$

For zeta potential, the analysis of variance (Table $4 \mathrm{~b}$ ) indicated that the model components of $B, B^{2}, C^{2}$ and $B C$ were significant ("probe $>\mathrm{P}$ " less than 0.05 ), but $A$ and $A C$, were not significant. Thus, the related components were eliminated because they had $\mathrm{P}$ values of more than
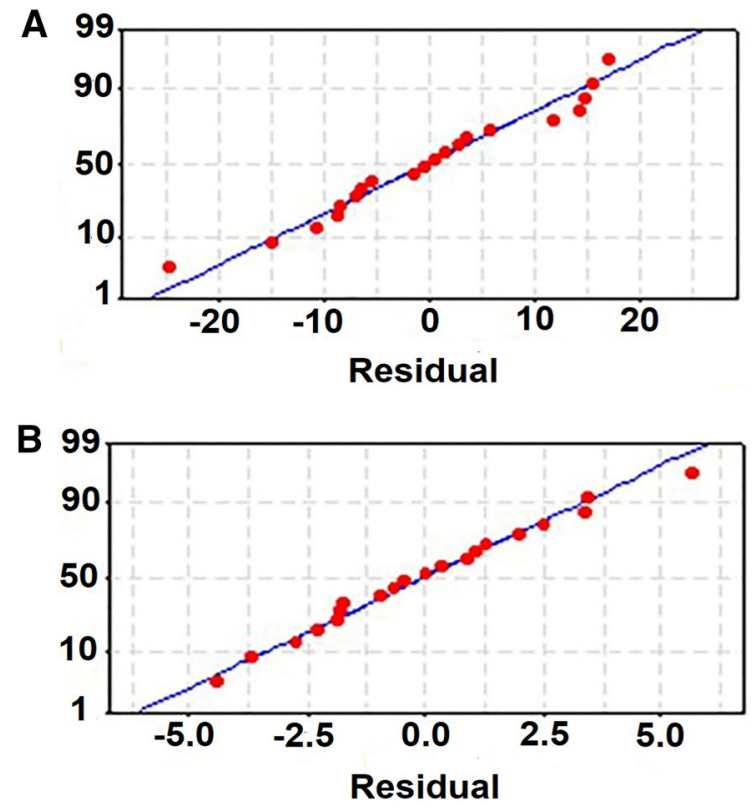

Fig. 1 Normal probability plot for $\mathbf{a}$ size and $\mathbf{b}$ or zeta potential

0.1 and also caused a decrease in the adjusted $R^{2}$ of the model $[30,34]$. Therefore, the simplified second-order

\begin{tabular}{|c|c|c|c|c|c|}
\hline Source & $d f$ & Sum of square & Mean square & $F$ value & $p$ value \\
\hline \multicolumn{6}{|l|}{ (a) } \\
\hline Mean vs total & 1 & 43223.61 & 43223.61 & & \\
\hline Linear vs mean & 3 & 528.20 & 176.07 & 2.02 & 0.1514 \\
\hline 2FI vs linear & 3 & 705.59 & 235.20 & 4.45 & 0.0233 \\
\hline Quadratic vs 2FI & 3 & 560.37 & 186.79 & 14.68 & 0.0005 \\
\hline Cubic vs Quadratic & 4 & 77.48 & 19.37 & 2.33 & 0.1693 \\
\hline Residual & 6 & 49.80 & 8.30 & & \\
\hline Total & 20 & 45145.06 & 2257.25 & & \\
\hline Source & $d f$ & Seq Sum of square & Mean square & $F$ value & $p$ value \\
\hline \multicolumn{6}{|l|}{ (b) } \\
\hline Mean vs total & 1 & $1.382 \mathrm{E}+005$ & $1.382 \mathrm{E}+005$ & & \\
\hline Linear vs Mean & 3 & 7680.22 & 2560.07 & 1.49 & 0.2546 \\
\hline 2FI vs linear & 3 & 11005.15 & 3668.38 & 2.90 & 0.0753 \\
\hline Quadratic vs 2FI & 3 & 14053.62 & 4684.54 & 19.57 & 0.0002 \\
\hline Cubic vs Quadratic & 4 & 1883.06 & 470.77 & 5.53 & 0.0327 \\
\hline Residual & 6 & 510.93 & 85.15 & & \\
\hline Total & 20 & $1.733 \mathrm{E}+005$ & 8666.41 & & \\
\hline
\end{tabular}
polynomial equation for ethosome preparation $(Y)$ was described instead of actual factors as follows:

$$
\begin{aligned}
Y_{\text {zeta }}= & -48.52+2.96 B+5.30 C-8.79 A B-2.85 B C \\
& -3.62 A^{2}+2.63 B^{2}+3.79 C^{2},
\end{aligned}
$$

Table 4 Analysis of variance (ANOVA) for a) size, b) zeta potential 
where $A, B$ and $C$ are phospholipid, ethanol and cholesterol concentrations, respectively. The regression equation obtained from analysis of variance (ANOVA) showed that the multiple correlation coefficient of $R^{2}$ for size and zeta potential is 0.9319 ; i.e., the model can illustrate $93.19 \%$; and also 0.9338 , i.e., the model can explain $93.38 \%$ parameters, respectively, in the responses. It should be attended that a $R^{2}$ value greater than 0.75 indicates the aptness of the model. The adjusted $R^{2}$ percent for size and zeta potential is 87.05 and 87.4 , respectively.

The ANOVA results in Table $4 \mathrm{a}, \mathrm{b}$ confirmed a satisfactory adjustment of the simplified quadratic model of the experimental data. It should be considered that the polynomial model is a reasonable approximation of the true functional relationship on a relatively small region of entire space of the independent variables [34].

The normal probability plot, Fig. 1a, b, shows the distribution of residual value. The normal probability plot, which is defined as the difference between the predicted (model) and observed (experimental) data, creates a straight line and residual value is normality distributed on both the sides of the line indicating that experimental point is reasonably aligned with the predicted value.
The relationships between ethosome composition factors and responses can be better understood by examining the series of contour plots. The three-dimensional response surface graphs (Figs. 2, 3, 4) were plotted to show the interaction of the variables.

Figure 2a, b shows the response of the interactive factors (the phospholipid amount and ethanol) when the cholesterol content was kept at 0.80 (W/W). Using constant amounts of phospholipid and increasing amounts of ethanol, the size response was increased. It should be noted that the increase in the size response was more apparent using high levels of phospholipid by $2-5 \%$, so that the smallest size is $110 \mathrm{~nm}$ and maximum size is $155 \mathrm{~nm}$. The increasing ethanol content may lead to weakness of vesicle membrane and subsequently, disruption of vesicle [35].

Zeta potentials in low phospholipid amounts (assuming constant) and ethanol from low to high values goes down to the negative numbers that are more stable. When ethanol amount was increased, zeta potential was more negative as ethanol provides a concentration-dependent surface negative charge to polar head region of phospholipid which avoids or at least delays the formation of vesicle aggregates, due to the electrostatic repulsions $[36,37]$. The addition of alcohol
Fig. 2 Effect and interactions of phospholipid and ethanol concentration on size and zeta potential responses, $\mathbf{a}, \mathbf{b} 3 \mathrm{D}$ plot and contour plot for size, $\mathbf{c}$, d 3D plot and contour plot for zeta potential
A

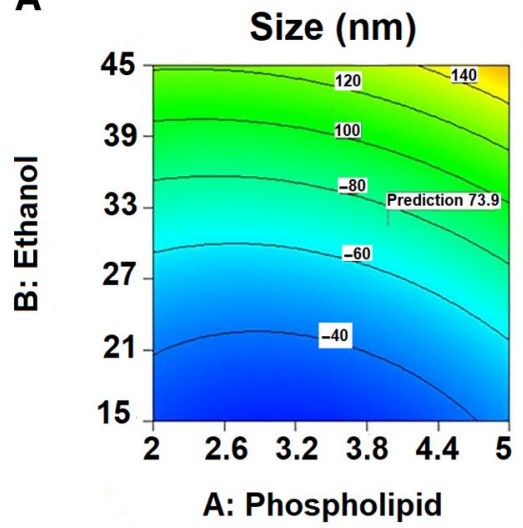

C

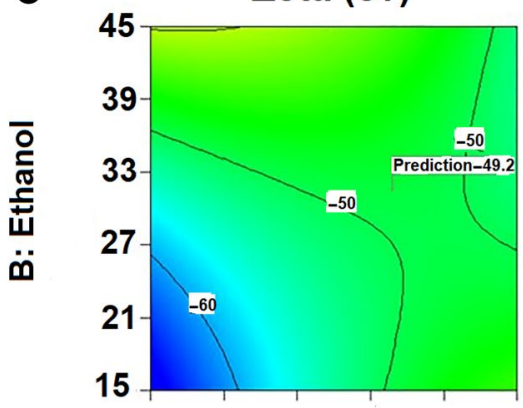

A: Phospholipid
B

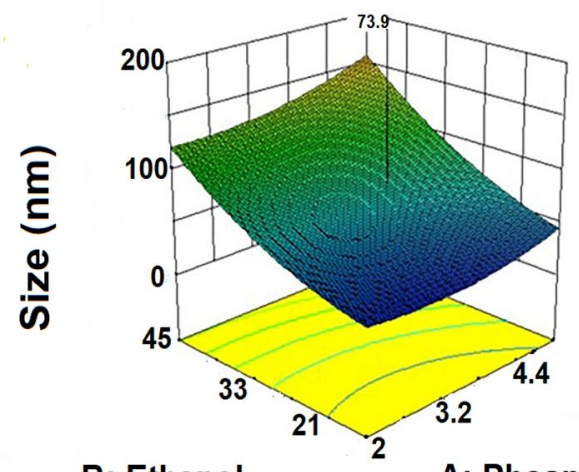

B: Ethanol

A: Phospholipid
D

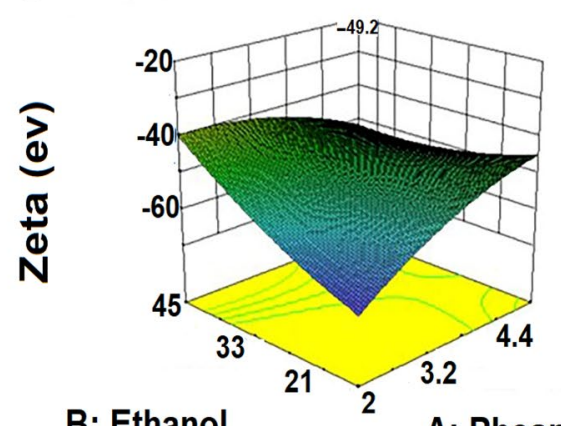

B: Ethanol

A: Phospholipid 
Fig. 3 Effect and interactions of cholesterol and phospholipid concentration on size and zeta potential responses, a, b 3D plot and contour plot for size, c, d 3D plot and contour plot for zeta potential

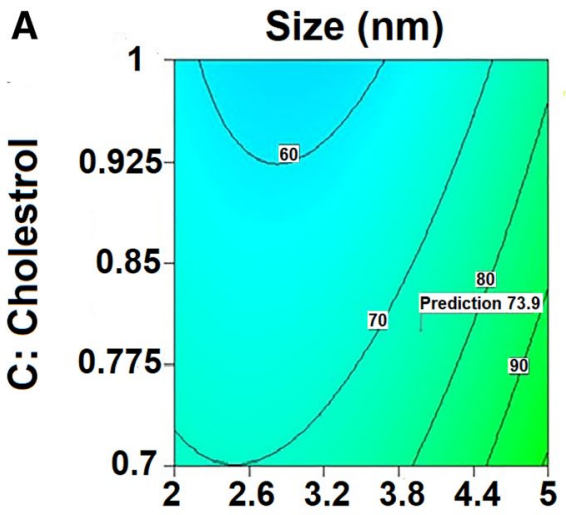

A: Phospholipid

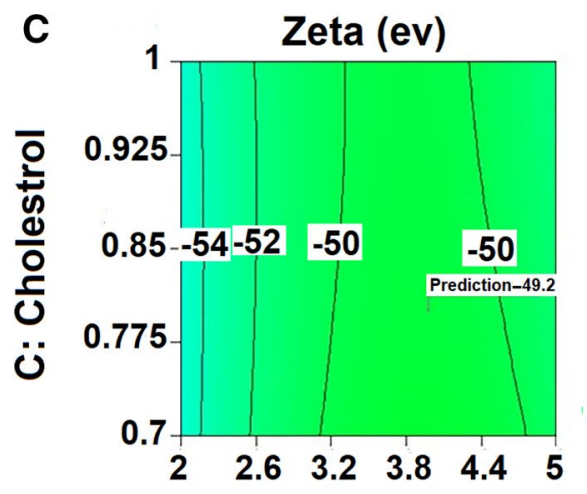

A: Phospholipid
B

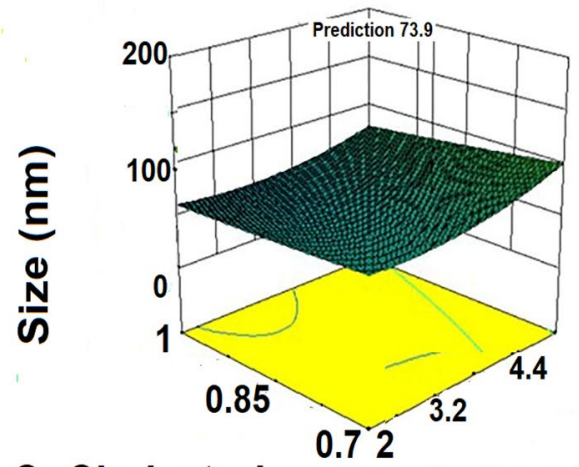

C: Cholestrol

A: Phospholipid

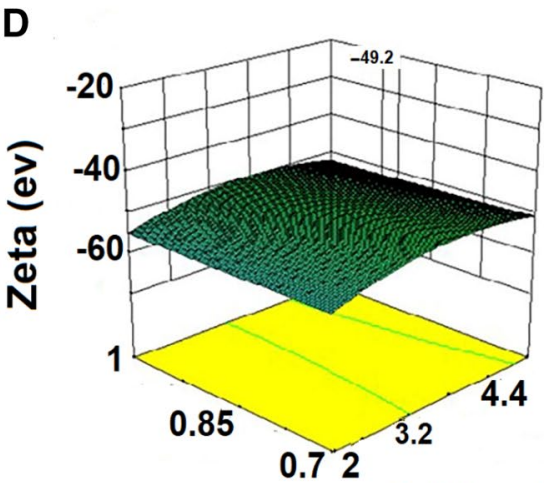

C: Cholestrol

A: Phospholipid

induces a transition in the charge of the vesicles from positive to negative [38].

When the amount of ethanol was held constant, by changing phospholipid concentration, the same changes happened and zeta values are more positive. In quantities exceeding 3.8 (W/W) phospholipids, ethanol changes from low to high percentages, where there is no significant effect on the zeta potential.

As shown in Fig. 3c, d when cholesterol is constant and the phospholipid increases, the size is increasing, gradually. If the cholesterol is $0.9 \mathrm{mg} / \mathrm{ml}$ or more, the size response does not change. If phospholipid levels were held constant, cholesterol does not affect zeta potential. Also, using a constant cholesterol amount, phospholipid changes have made low changes on zeta potential.

When the amount of cholesterol was held constant, the size response of the system was decreased as the phospholipid and ethanol content increased, first slowly and then rapidly. The change in the slope occurs with higher phospholipid and ethanol contents, when the amount of both of them is set to the higher value. Using a constant cholesterol amount, the decrease in the zeta potential response with decreasing phospholipid and ethanol contents occurred. The change in phospholipid and cholesterol does not affect the zeta potential and this may be because phospholipid and cholesterol do not alter the net charge of the vesicles. With decreasing phospholipid and ethanol, the zeta potential decreased, as ethanol increases vesicles net charge.

Figure $4 \mathrm{a}$, b shows that when cholesterol amount is held constant, changes in the amount of ethanol, increases the size. Also, at constant values of ethanol. the cholesterol changes did not significant effected the size response.

If ethanol amount was held constant, cholesterol changes have not significantly changed zeta potential. Also, if the amount of cholesterol is kept constant, the effect of different amounts of ethanol on zeta potential varies only between -50 and $-46 \mathrm{~mL}$, aand is constant for the rest of the cases.

At constant values of ethanol, cholesterol changes did not have significant effect on the size response, because cholesterol increases the membrane rigidity and then more stability.

The optimum amounts of ethanol, cholesterol and phospholipid determined using Design Expert were 45\%, 1.5\% and $5 \%$, respectively, for optimum size and zeta potential responses.

The FESEM image of optimized formulation of ethosomes (Fig. 5) showed the formation of spherical and uniform vesicles with 20-22-nm diameter. The FESEM image 
Fig. 4 Effect and interactions of ethanol and cholesterol concentration on size and zeta potential responses, a, b $3 \mathrm{D}$ plot and contour plot for size, $\mathbf{c}$, d 3D plot and contour plot for zeta potential

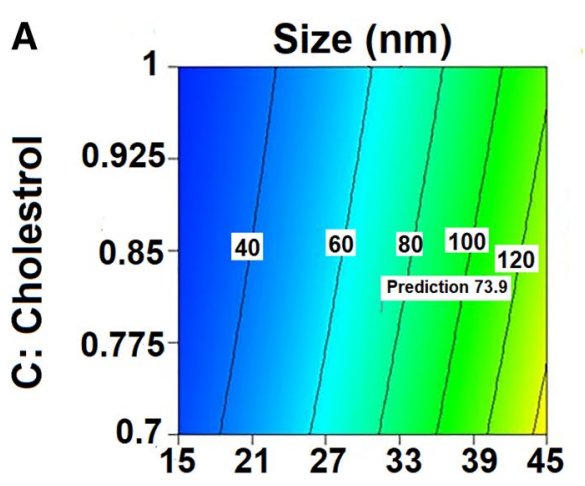

B: Ethanol

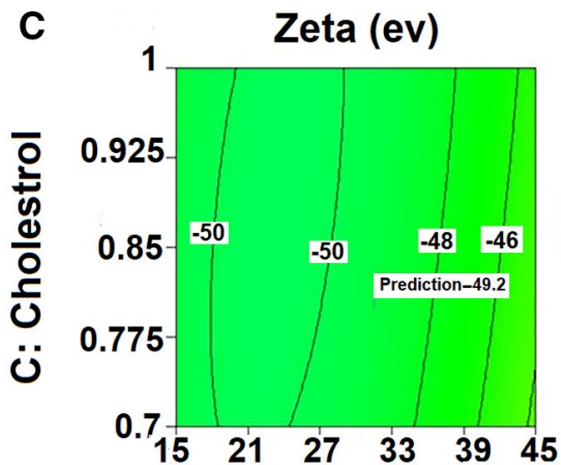

B: Ethanol

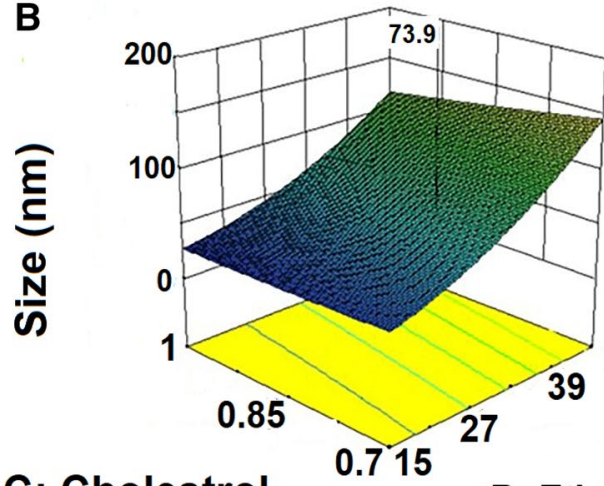

C: Cholestrol

B: Ethanol

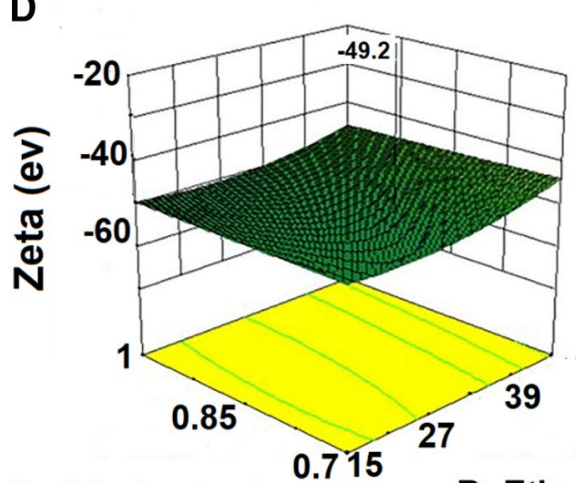

C: Cholestrol

B: Ethanol

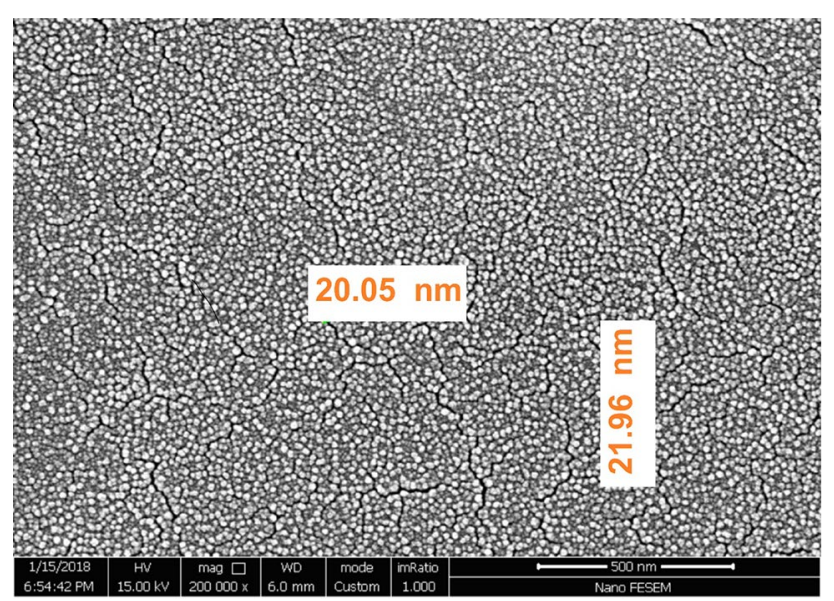

Fig. 5 Ethosome FESEM image, at magnification of 200,000x

of optimized formula indicated that the important factors concentration (phospholipid, ethanol and cholesterol) had been selected, precisely. Figure 6 shows the particle size distribution of optimum ethosome. The size of ethosome could be influenced by factors such as ethanol: phospholipid ratio and concentration of cholesterol.

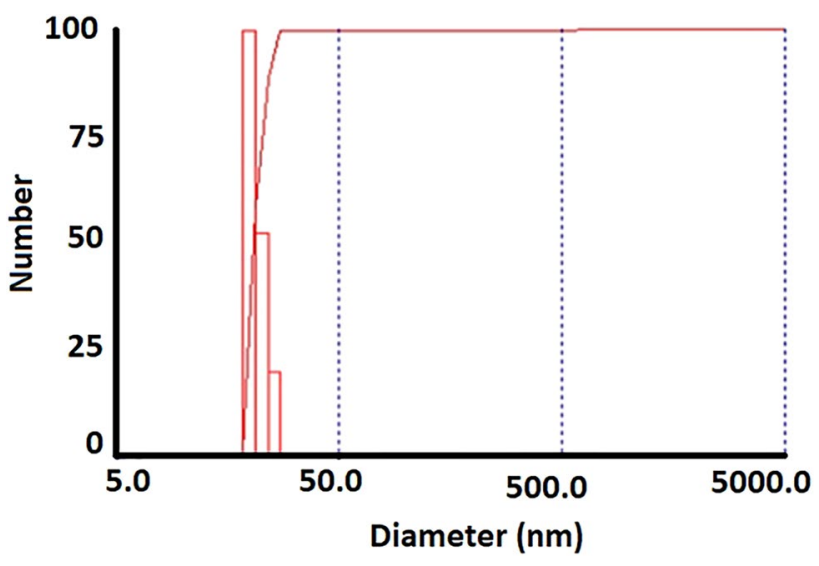

Fig. 6 Size distribution of the ethosomal formulation

The zeta potentials of the ethosomes were -43 to -63 (Fig. 7). Negative results indicate that ethosome nanoparticles are stable [39].

PDI was $0.15 \pm 0.02$; this result demonstrated that the nanoparticles were monodisperse in the solution. Entrapment efficacy (EE) was $98 \pm 1 \%$. The high hydrophobicity of TQ had led to its high EE. 
Fig. 7 The zeta potential of ethosome

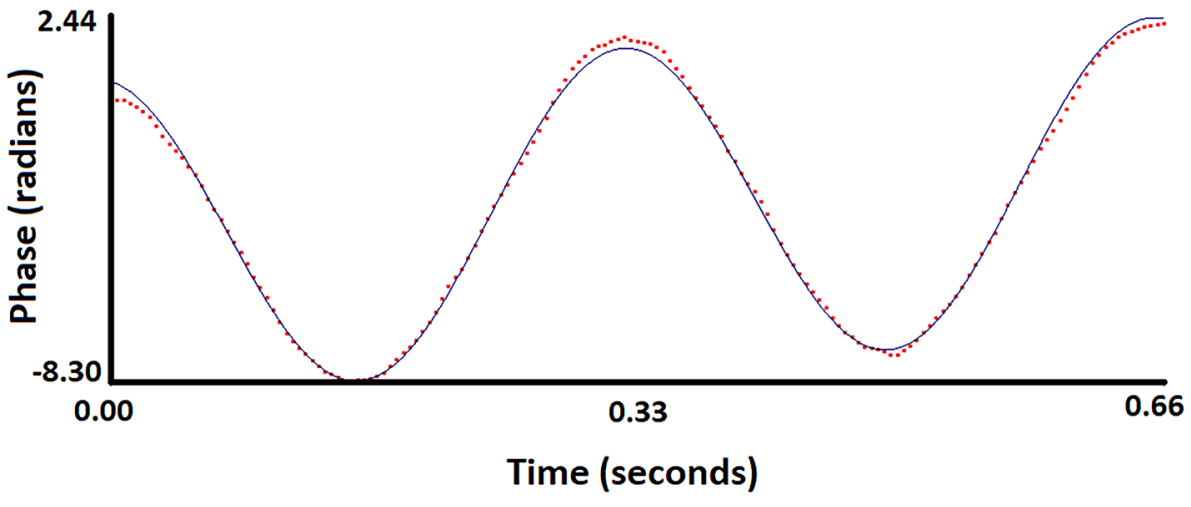

TQ-Eth indicated its characteristic UV-visible peak at about $230 \mathrm{~nm}$ (Fig. 8).

Fig. 8 UV-visible spectrum significant $(P \leq 0.005)$ for ethosomes at 90th day [31, 40, 41].

\section{TQ-Eth}

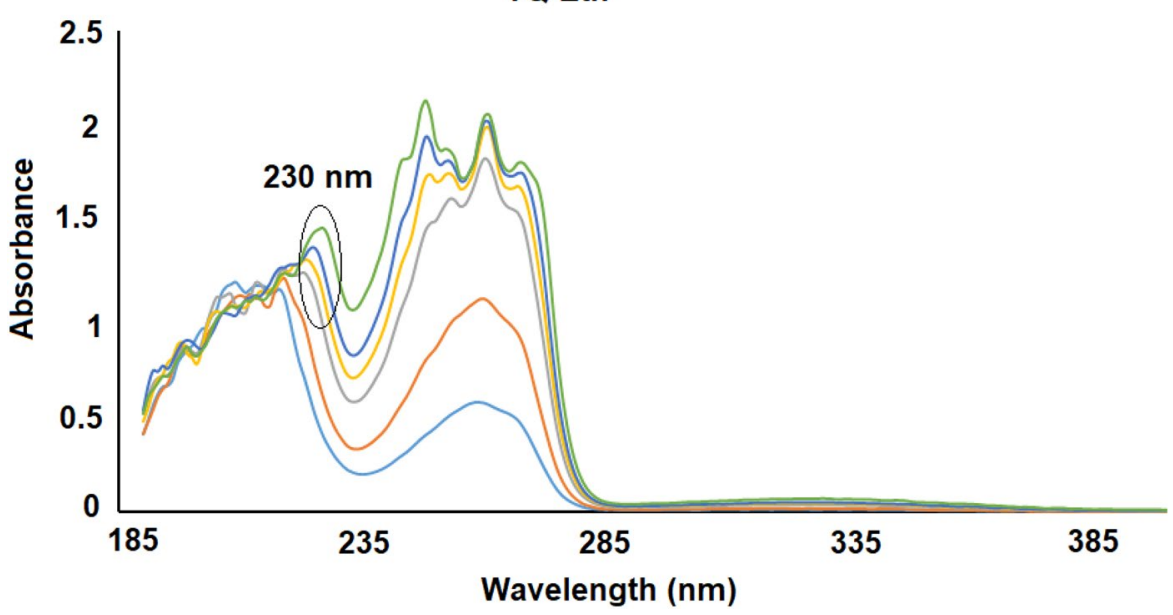

Table 5 The physical stability of tacrolimus-loaded ethosomes $(\mathrm{T}=4$ $\left.{ }^{\circ} \mathrm{C}\right)$

\begin{tabular}{llllll}
\hline Formulation & $\begin{array}{l}\text { Duration } \\
\text { of storage } \\
\text { (Day) }\end{array}$ & PDI & EE \% & $\begin{array}{l}\text { Zeta } \\
\text { potential } \\
(\mathrm{mV})\end{array}$ & Size \\
\hline TQ & 0 & $0.14 \pm 0.03$ & $98 \pm 1$ & -61 & $20 \pm 1$ \\
& 30 & $0.16 \pm 0.03$ & $98 \pm 2$ & -60 & $22 \pm 1$ \\
& 60 & $0.20 \pm 0.05$ & $96 \pm 1$ & -56 & $21 \pm 2$ \\
& 90 & $0.17 \pm 0.01$ & $94 \pm 1$ & -45 & $22 \pm 1$ \\
\hline
\end{tabular}

\section{Physical stability study}

Physical stability of TQ-Eth related to particle size, size distribution (PDI), entrapment efficacy (EE) and zeta potential was tested until 90 days by storage of them at temperature $4 \pm 0.5^{\circ} \mathrm{C}$ (Table 5). Nanoparticles size, PDI, EE and zeta potential were $22 \pm 1,0.17 \pm 0.01,94 \pm 1.5 \%$ and -45 after 90 days, respectively. Changes in recorded parameters were

\section{TQ release curve}

The in vitro release profiles of TQ-Eth were evaluated at $37{ }^{\circ} \mathrm{C}$ in PBS buffer $(\mathrm{pH}=7.4)$ and are shown in Fig. 9. TQ showed $45.84 \%$ release within $10 \mathrm{~h}$ followed by more sustained release from the ethosome nanoparticles until $24 \mathrm{~h}$ (78.48\%). Approximately, 99\% of TQ was released from nanoparticles within $48 \mathrm{~h}$. The drugs in the layer of ethosomes diffuse out through the surface layer. This result in Fig. 9 conclude that the drug release from this formulation depends on the concentration of drug.

\section{MTT assay}

MTT assays were performed to determine the effect of, free TQ and ethosomal TQ, on the cell viability in MCF-7 cell line (Fig. 10). We compared the ability of TQ, and its ethosomal formulation to inhibit cell viability in MCF-7 cell line. IC50 values of TQ, and TQ nanoparticles were found to be 


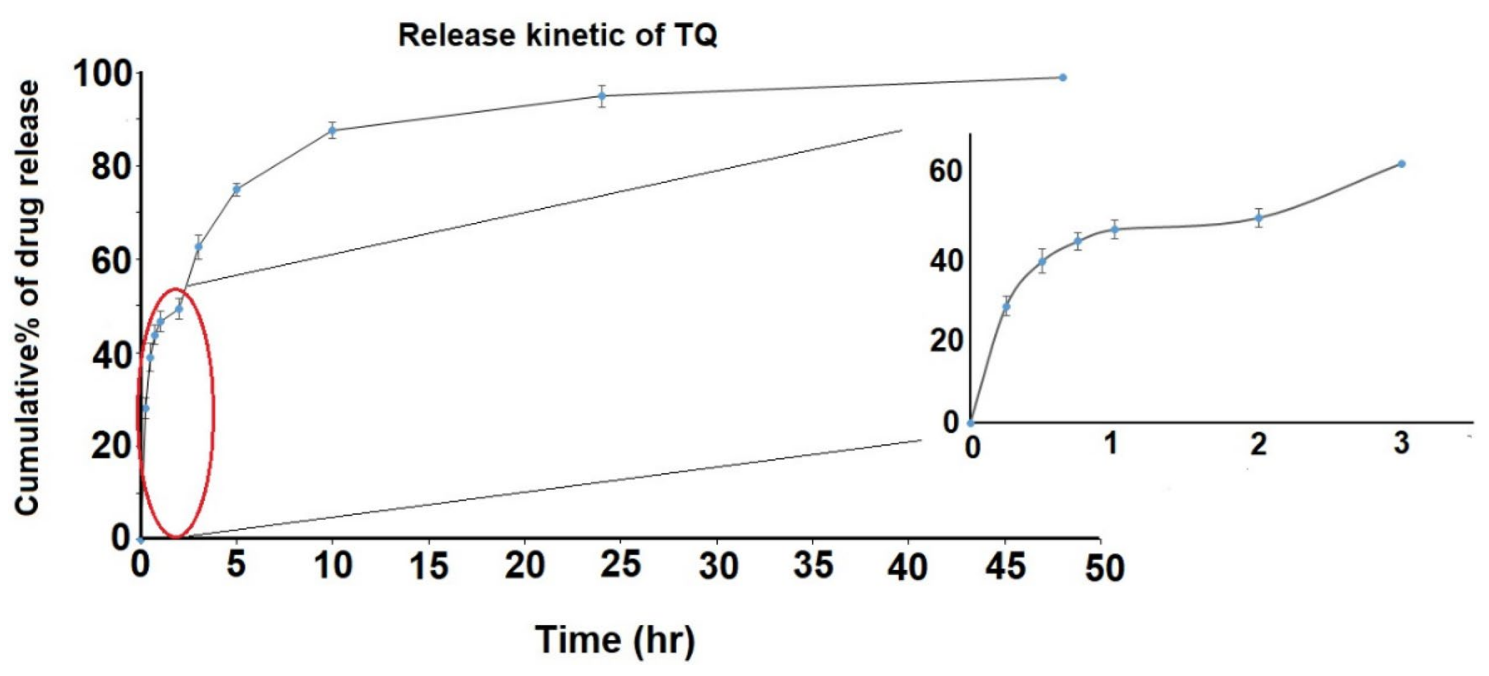

Fig. 9 TQ release from nano-formulations

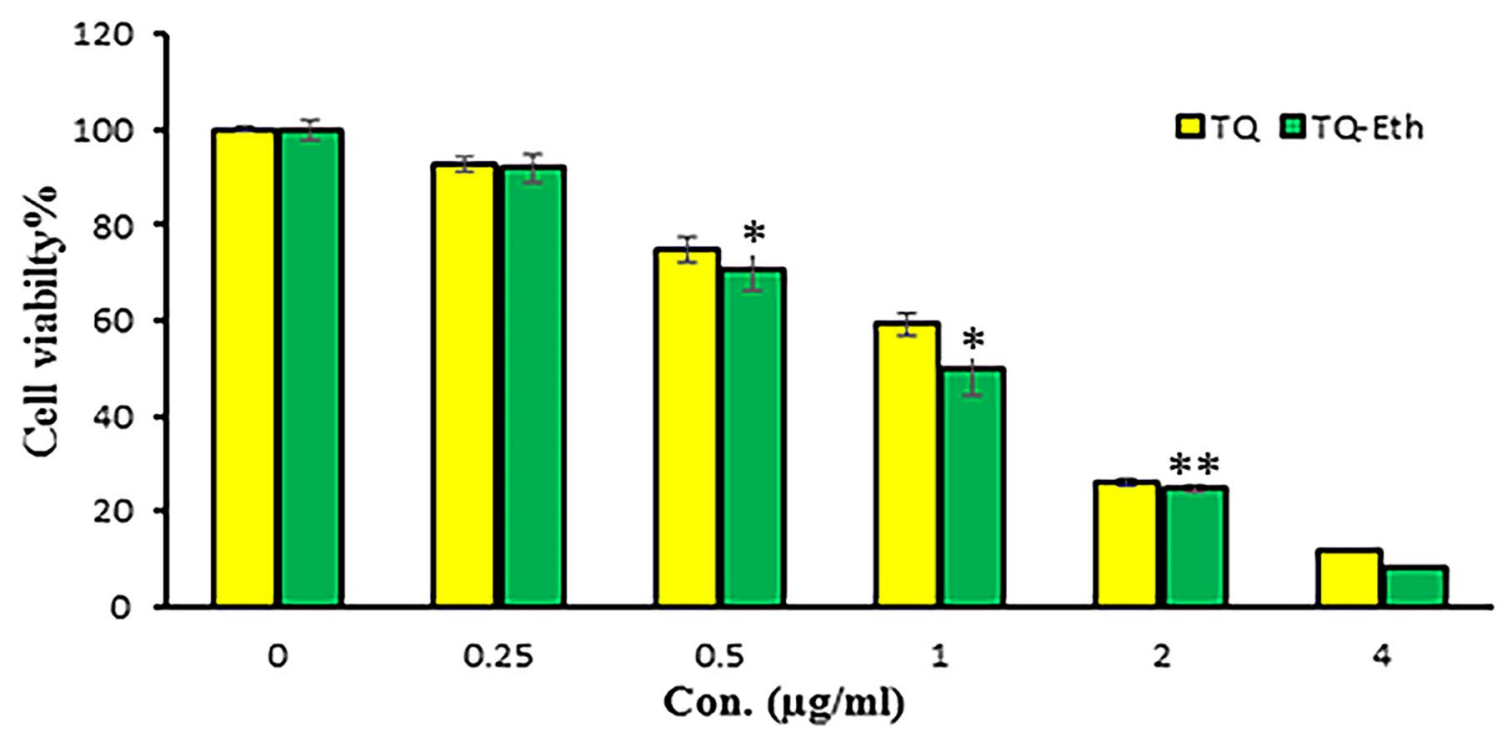

Fig. 10 Cytotoxic activity of TQ and TQ-Eth

$500,136.3(\mathrm{mg} / \mathrm{ml})$, respectively. The ethosomal TQ showed high ability to inhibit cell growth in vitro. Cytotoxicity of samples was compared with control (untreated) cells that were considered as 100 percent viable [19].

As shown in Fig. 10, the anti-proliferation effect was in the order of TQ-Eth $>$ TQ. The results depicted that TQEth showed stronger anti-proliferative activity than free TQ in MCF-7 cell lines $(P<0.05)$. It is due to that TQEth can increase the intracellular concentrations of TQ. The TQ-loaded NPs showed a higher cytotoxicity than free TQ because of their active site and surface area.

\section{Conclusions}

The present study provided an optimized and high efficiency procedure for ethosome nanoparticle preparation which could be used for TQ encapsulation. Using a statistical design for screening and optimization, it is also possible to quickly identify important factors and interact with them. The objective of RSM application in the study was finding the optimum conditions for nanoparticle production by determining a region of the factor space, where the operating specifications are satisfied. RSM is used to study the effects of several factors that influence responses by varying them simultaneously in a limited number of experiments. 
Ethosome nanoparticles were successfully produced. A second-order model equation was suggested by the analysis. The response of the system by the model at optimal conditions is confirmed by the experimental data, thus confirming the validity of the model. ANOVA results confirmed a satisfactory adjustment of the models to experimental data. In summary, the optimized formulation of ethosome is applicable for drug delivery, chemotherapeutic agents in cancer therapy and cosmetic application for drug delivery because they enhanced permeation and skin deposition.

Acknowledgements We would like to thank the University of Tehran, University of Tehran science and technology Park (Grant No. 96080) for providing financial and instrumental supports in this work.

\section{Compliance with ethical standards}

Conflict of interest The authors have declared that no conflicting interests exist

Open Access This article is licensed under a Creative Commons Attribution 4.0 International License, which permits use, sharing, adaptation, distribution and reproduction in any medium or format, as long as you give appropriate credit to the original author(s) and the source, provide a link to the Creative Commons licence, and indicate if changes were made. The images or other third party material in this article are included in the article's Creative Commons licence, unless indicated otherwise in a credit line to the material. If material is not included in the article's Creative Commons licence and your intended use is not permitted by statutory regulation or exceeds the permitted use, you will need to obtain permission directly from the copyright holder. To view a copy of this licence, visit http://creativecommons.org/licenses/by/4.0/.

\section{References}

1. Zhang, Y.T., Shen, L.-N., Zhao, J.-H., Feng, N.-P.: Evaluation of psoralen ethosomes for topical delivery in rats by using in vivo microdialysis. Int. J. Nanomed. 9, 669-678 (2014)

2. Tyagi, L.K., Kumar, S., Maurya, S.S., Kori, M.L.: Ethosomes: novel vesicular carrier for enhanced transdermal drug delivery system. Bull. Pharm. Res. 3(1), 6-13 (2013)

3. Nandure, H.P., Puranik, P., Giram, P., Lone, V.: Ethosome: A Novel Drug Carrier. Int. J. Pharm. Res. Allied Sci. 2(3), 2277 3657 (2013)

4. Pathan, I.B., Jaware, B.P., Shelke, S., Ambekar, W.: Curcumin loaded ethosomes for transdermal application: Formulation, optimization, in-vitro and in-vivo study. J. Drug Del. Sci. Tech. 44, 49-57 (2018)

5. Jangdey, M.S., Gupta, A., Saraf, S., Saraf, S.: Development and optimization of apigenin-loaded transfersomal system for skin cancer delivery: in vitro evaluation. Artif. Cells Nanomed. B. 45(7), 1452-1462 (2017)

6. Smith, N., Gilmour, S., Rastall, R.: Statistical optimization of enzymatic synthesis of derivatives of trehalose and sucrose. Enzyme Microb. Technol. 21(5), 349-354 (1997)

7. Prakash, G., Srivastava, A.K.: Statistical media optimization for cell growth and azadirachtin production in Azadirachta indica (A. Juss) suspension cultures. Process. Biochem. 40(12), 3795-800 (2005).
8. Fakhri, A.: Investigation of mercury (II) adsorption from aqueous solution onto copper oxide nanoparticles: optimization using response surface methodology. Process. Saf. Environ. 93, 1-8 (2015)

9. Zu, Y., Zhang, Y., Zhao, X., Zhang, Q., Liu, Y., Jiang, R.: Optimization of the preparation process of vinblastine sulfate (VBLS)loaded folateconjugated bovine serum albumin (BSA) nanoparticles for tumor-targeted drug delivery using response surface methodology (RSM). Int. J. Nanomed. 4, 321 (2009)

10. Li, F., Sun, J., Zhu, H., Wen, X., Lin, C., Shi, D.JC. Preparation and characterization novel polymer-coated magnetic nanoparticles as carriers for doxorubicin. Colloids. Surf. B. 88(1), 58-62 (2011).

11. Abdel Messih, H.A., Ishak, R.A., Geneidi, A.S., Mansour, S.: Nanoethosomes for transdermal delivery of tropisetron $\mathrm{HCl}$ : multi-factorial predictive modeling, characterization, and ex vivo skin permeation. Drug Dev. Ind. Pharm. 43(6), 958-971 (2017)

12. Woo, F.Y., Basri, M., Masoumi, H.R.F., Ahmad, M.B., Ismail, M.: Formulation optimization of galantamine hydrobromide loaded gel drug reservoirs in transdermal patch for Alzheimer's disease. Int. J. Nanomedicine. 10, 3879-3886 (2015)

13. Mahmoud, Y.K., Abdelrazek, H.M.A.: Cancer: Thymoquinone antioxidant/pro-oxidant effect as potential anticancer remedy. Biomed. Pharmacother. 115, 108783 (2019)

14. Guan, D., Li, Y., Peng, X., Zhao, H., Mao, Y., Cui, Y.: Thymoquinone protects against cerebral small vessel disease: Role of antioxidant and anti-inflammatory activities. J. Biol Regul Homeost Agents. 32(2), 225-231 (2018)

15. Fararh, K., Atoji, Y., Shimizu, Y., Shiina, T., Nikami, H., Takewaki, T.: Mechanisms of the hypoglycaemic and immunopotentiating effects of Nigella sativa L. oil in streptozotocin-induced diabetic hamsters. Res. Vet. Sci. 77(2),123-9 (2004).

16. Ahmad, S., Beg, Z.H.: Hypolipidemic and antioxidant activities of thymoquinone and limonene in atherogenic suspension fed rats. Food. Chem. 138(2-3), 1116-1124 (2013)

17. Majdalawieh, A.F., Fayyad, M.W., Nasrallah, G.K.: Anti-cancer properties and mechanisms of action of thymoquinone, the major active ingredient of Nigella sativa. Crit. Rev. Food. Sci. Nutr. 57(18), 3911-3928 (2017)

18. Yang, Y., Bai, T., Yao, Y-L., Zhang, D-Q., Wu, Y-L., Lian, L-H.: Upregulation of SIRT1-AMPK by thymoquinone in hepatic stellate cells ameliorates liver injury. Toxicol. Lett. 262, 80-91 (2016).

19. Shaterzadeh-Yazdi, H., Noorbakhsh, M.-F., Hayati, F., Samarghandian, S., Farkhondeh, T.: Immunomodulatory and Antiinflammatory Effects of Thymoquinone. Cardiovasc. Haematol. Disord. Drug Targets. 18(1), 52-60 (2018)

20. Bimonte, S., Albino, V., Barbieri, A., Tamma, M.L., Nasto, A., Palaia, R.: Dissecting the roles of thymoquinone on the prevention and the treatment of hepatocellular carcinoma: an overview on the current state of knowledge. Infect. Agents. Cancer. 14(1), 10 (2019)

21. Qadi, S.A., Hassan, M.A., Sheikh, R.A., Baothman, O.A., Zamzami, M.A., Choudhry, H., et al.: Thymoquinone-Induced Reactivation of Tumor Suppressor Genes in Cancer Cells Involves Epigenetic Mechanisms. Epigenetics Insights. 12, 1-9 (2019)

22. Samarghandian, S., Azimi-Nezhad, M., Farkhondeh, T.: Thymoquinone-induced antitumor and apoptosis in human lung adenocarcinoma cells. J. Cell. Physiol. 234(7), 10421-10431 (2019)

23. Ke, W., Zha, Z., Mukerabigwi, J.F., Chen, W., Wang, Y., He, C.: Matrix metalloproteinase-responsive multifunctional peptidelinked amphiphilic block copolymers for intelligent systemic anticancer drug delivery. Bioconjugate. Chem. 28(8), 2190-2198 (2017)

24. Odeh, F., Ismail, S.I., Abu-Dahab, R., Mahmoud, I.S., Al Bawab, A.: Thymoquinone in liposomes: a study of loading efficiency 
and biological activity towards breast cancer. Drug Deliv. 19(8), 371-377 (2012)

25. Surekha, R., Sumathi, T.: An efficient encapsulation of thymoquinone using solid lipid nanoparticle for brain targeted drug delivery: physicochemical characterization, pharmacokinetics and biodistribution studies. Int. J. Pharm. Clin. Res. 8(12), 1616-1624 (2016)

26. Abdelwahab, S.I., Sheikh, B.Y., Taha, M.M.E., How, C.W., Abdullah, R., Yagoub, U., El-Sunousi, R., Eid, EE.: Thymoquinone-loaded nanostructured lipid carriers: preparation, gastroprotection, in vitro toxicity, and pharmacokinetic properties after extravascular administration. Int. J. Nanomed. 8, 2163-2172. (2013).

27. Vijayakumar, M., Sathali, A.H., Arun, K.: Formulation and evaluation of diclofenac potassium ethosomes. Int. J. Pharm. Pharm. Sci. 2(4), 82-86 (2010)

28. Peram, M.R., Jalalpure, S., Kumbar, V., Patil, S., Joshi, S., Bhat, K.: Factorial design based curcumin ethosomal nanocarriers for the skin cancer delivery: in vitro evaluation. J. Liposome. Res. 29(3), 291-311 (2019)

29. reza Ariamoghaddam, A., Ebrahimi-Hosseinzadeh, B., HatamianZarmi, A., Sahraeian R.: In vivo anti-obesity efficacy of curcumin loaded nanofibers transdermal patches in high-fat diet induced obese rats. Mater. Sci. Eng. C. 92, 161-71(2018).

30. Montgomery, D.C.: Design and analysis of experiments. Wiley, Hoboken (2017).

31. Mahmood, S., Mandal, U.K., Chatterjee, B.: Transdermal delivery of raloxifene $\mathrm{HCl}$ via ethosomal system: Formulation, advanced characterizations and pharmacokinetic evaluation. Int. J. Pharm. 542(1-2), 36-46 (2018)

32. Mohammed, M., Makky, A., Abdellatif, M.: Formulation and characterization of ethosomes bearing vancomycin hydrochloride for transdermal delivery. Int. J. Pharm. Pharm. Sci. 6(11), 190-194 (2014)

33. Lin, W., Xie, X., Yang, Y., Fu, X., Liu, H., Yang, Y.: Thermosensitive magnetic liposomes with doxorubicin cell-penetrating peptides conjugate for enhanced and targeted cancer therapy. Drug. Deliv. 23(9), 3436-3443 (2016)

34. Ebrahimi, B., Shojaosadati, S., Ranaie, S., Mousavi, S.: Optimization and evaluation of acetylcholine esterase immobilization on ceramic packing using response surface methodology. Process Biochem. 45(1), 81-87 (2010)

35. Babaie, S., Ghanbarzadeh, S., Davaran, S., Kouhsoltani, M., Hamishehkar, H.: Nanoethosomes for dermal delivery of lidocaine. Adv. Pharm. Bull. 5(4), 549 (2015)

36. Jain, S., Patel, N., Madan, P., Lin, S.: Quality by design approach for formulation, evaluation and statistical optimization of diclofenac-loaded ethosomes via transdermal route. Pharm. Dev. Technol. 20(4), 473-489 (2015)

37. Touitou, E., Dayan, N., Bergelson, L., Godin, B., Eliaz, M.: Ethosomes-novel vesicular carriers for enhanced delivery: characterization and skin penetration properties. J. Control Release. 65(3), 403-418 (2000)

38. Ghari, T., Salmannejad, F., Toliyat, T.: Risperidone permeation enhancement through the skin from ethosomal carriers versus liposomal carriersand hydroalcoholic solutions. Curr. Res. Biological. Pharm. Sci. 4(3), 1-6 (2015)

39. Soni, P., Kaur, J., Tikoo, K.: Dual drug-loaded paclitaxel-thymoquinone nanoparticles for effective breast cancer therapy. J. Nanoparticle. Res. 17(1), 18 (2015)

40. Akiladevi, D., Basak, S.: Ethosomes-a noninvasive approach for transdermal drug delivery. Int. J. Curr. Pharm. Res. 2(4), 1-4 (2010)

41. Rakesh, R., Anoop, K.: Formulation and optimization of nanosized ethosomes for enhanced transdermal delivery of cromolyn sodium. J. Pharm. Bioallied Sci. 4(4), 333-340 (2012)

Publisher's Note Springer Nature remains neutral with regard to jurisdictional claims in published maps and institutional affiliations.

\section{Affiliations}

\section{Shilan Nasri ${ }^{1} \cdot$ Bahman Ebrahimi-Hosseinzadeh $^{1}$ (D Mahdi Rahaie ${ }^{1} \cdot$ Ashrafalsadat Hatamian-Zarmi $^{1}$. Razi Sahraeian'}

Bahman Ebrahimi-Hosseinzadeh

bahman.ebrahimi@ut.ac.ir

Mahdi Rahaie

mrahaie@ut.ac.ir
1 Department of Life Science Engineering, Faculty of New Sciences and Technologies, University of Tehran, Tehran 1439957131, Iran

2 Iran Polymer and Petrochemical Institute, Tehran, Iran 